\title{
EMERGÊNCIA E VIGOR DE SEMENTES DE AMENDOIM TRATADAS COM COBALTO E MOLIBDÊNIO
}

Tatiane Sanches Jeromini ${ }^{1}$; Renato Téo de Barros ${ }^{2}$; Thais Soares Pereira ${ }^{3}$; Givanildo Zildo da Silva ${ }^{4}$; Cibele Chalita Martins ${ }^{5}$

'Mestrando em Agronomia (Produção Vegetal), FCAV/UNESP, Jaboticabal, SP, renatotbarros@hotmail.com; ${ }^{2}$ Mestrando em Agronomia (Produção Vegetal), FCAV/UNESP, Jaboticabal, SP; ${ }^{3}$ Mestranda em Agronomia (Produção Vegetal), FCAV/UNESP, Jaboticabal, SP; ${ }^{4}$ Pós-doutorando em Agronomia (Produção Vegetal), Universidade Federal de Goiás, Jataí, GO; ${ }^{5}$ Docente da FCAV/UNESP, Jaboticabal, SP.

RESUMO: O objetivo do trabalho foi avaliar a emergência e vigor de sementes de amendoim tratadas com cobalto e molibdênio. $\mathrm{O}$ trabalho foi conduzido utilizando dois lotes de sementes de amendoim da cultivar Runner IAC886 submetidas a cinco tratamentos, sendo eles: testemunha, água e três dosagens de Raynitro $^{\circledR}, 1,0 \mathrm{ml}, 1,5 \mathrm{ml}$ e 2,0 $\mathrm{ml} \mathrm{kg}^{-1}$ de sementes, fornecendo $5,7 \mathrm{mg}$ de Co e $68 \mathrm{mg}$ de $\mathrm{Mo} ; 8,55$ mg de Co e $102 \mathrm{mg}$ de Mo; $114 \mathrm{mg}$ de Co e $136 \mathrm{mg}$ de Mo, respectivamente. Foram avaliados os teores de água, porcentagem e primeira contagem de emergência, porcentagem de emergência em campo, índice de velocidade de emergência e tempo médio de emergência. O delineamento para os testes laboratoriais foi em delineamento inteiramente casualizado com quatro repetições de 50 sementes e para testes em campo foi utilizado delineamento em blocos casualizados com quatro repetições de 50 sementes. A aplicação de cobalto e molibdênio via semente não interfere na emergência de sementes de amendoim, enquanto que para o vigor o tratamento das sementes com estes micronutrientes prejudica a porcentagem e velocidade de emergência, não sendo recomendado no estabelecimento da cultura.

Palavras-chave: Arachis hypogaea L., germinação, emergência em campo.

\section{INTRODUÇÃO}

A produção de amendoim no Brasil na safra 2017/2018 foi de 505,2 mil toneladas, sendo que 90\% desta produção está concentrada no estado de São Paulo, nas regiões da Alta Paulista e Alta Mogiana (CONAB, 2018). A cultura tem destaque na reforma de canaviais, pois além de melhorar a fertilidade do solo, reduz a ocorrência de pragas, doenças e plantas daninhas, além de ser fonte de renda para o produtor (DOMINATO, 2010).

O amendoim, assim como outras leguminosas, dispensa a utilização de nitrogênio para adubação devido à fixação simbiótica. Para aumentar a eficiência desta fixação são utilizados micronutrientes que participam deste processo, como cobalto $(\mathrm{Co})$ e molibdênio (Mo). O Co é essencial aos microrganismos fixadores de $\mathrm{N}$ enquanto que o Mo faz parte da composição da enzima nitrogenase (VIEIRA, 1998). 
O uso de Co e Mo no desenvolvimento da cultura do amendoim é de grande importância e já foi abordado em vários trabalhos, entretanto, não se conhece o comportamento das sementes dessa cultura quando submetidas a tratamentos com estes nutrientes em relação à germinação e vigor. Assim, objetivou-se avaliar a emergência e vigor de sementes de amendoim tratadas com cobalto e molibdênio.

\section{MATERIAIS E MÉTODOS}

O trabalho foi conduzido no Laboratório de Análises de Sementes da Faculdade de Ciências Agrárias e Veterinárias da Universidade Estadual Paulista "Júlio de Mesquita Filho" Câmpus de Jaboticabal, Jaboticabal - SP. Dois lotes de sementes da cultivar Runner IAC 886 foram submetidos a cinco tratamentos, sendo eles: testemunha, água e três dosagens de Raynitro ${ }^{\circledR}$ (6\% de molibdênio (Mo) e $1 \%$ de cobalto (Co)), 1,0 ml, 1,5 ml e 2,0 ml kg-1 de sementes, fornecendo 5,7 mg de Co e 68 $\mathrm{mg}$ de Mo; 8,55 mg de Co e $102 \mathrm{mg}$ de Mo; $114 \mathrm{mg}$ de Co e $136 \mathrm{mg}$ de Mo, respectivamente Foram realizadas as seguintes determinações e avalições:

Teor de água - realizado pelo método da estufa, com subamostras de 5,0 $\mathrm{g}$ de sementes as quais foram expostas a $105 \pm 3{ }^{\circ} \mathrm{C}$ por 24 horas (BRASIL, 2009).

Emergência - realizada utilizando-se quatro repetições de 50 sementes dispostas em caixas plásticas transparentes de 15,0 × 26,0 x 9,5 cm dispostas sob substrato composto por solo + areia (1:1) umedecidos a fim de manter $60 \%$ da capacidade de campo do substrato. No $10^{\circ}$ dia após a semeadura foram contabilizadas as plântulas normais (BRASIL, 2009). Este substrato utilizado foi necessário visando a menor incidência de fungos nas sementes.

Primeira contagem de emergência - realizada conjuntamente com o teste de emergência e contabilizado as plântulas normais realizada ao $5^{\circ}$ dia após a semeadura (BRASIL, 2009).

Emergência de plântulas em campo - realizada com quatro subamostras de 50 sementes dispostas em sulcos de 2,0 m comprimento, espaçados a $0,9 \mathrm{~m}$, a uma profundidade de dois centímetros, com contagens diárias do quinto até o $10^{\circ}$ dia após a semeadura e os resultados foram expressos em porcentagem.

Índice de velocidade e tempo médio de emergência - realizada conjuntamente com a emergência em campo computando-se o número de plântulas emergidas por dia e aplicando-se a fórmula proposta por MAGUIRE (1962) e LABOURIAU \& VALADARES (1976)

O delineamento para os testes laboratoriais foi em delineamento inteiramente casualizado com quatro repetições e para testes em campo foi utilizado delineamento em blocos casualizados com quatro repetições. Os resultados obtidos foram submetidos a análise de variância e quando significativo as médias foram comparadas pelo teste de Tukey a 5\% de probabilidade. 


\section{RESULTADOS E DISCUSSÃO}

Foi possível observar efeito da aplicação de Co e Mo apenas para as variáveis emergência, emergência de plântulas em campo e índice de velocidade de emergência de sementes (Tabela 1 e 2).

Tabela 1. Resumo da análise de variância para emergência (E), primeira contagem de germinação (PC), emergência em campo (EC), índice de velocidade de emergência (IVE) e tempo médio de emergência (TME) de sementes de amendoim submetidas à tratamentos com cobalto e molibdênio.

\begin{tabular}{lcccccc}
\hline \multirow{2}{*}{ Causas de variação } & \multicolumn{7}{c}{ Quadrado médio } \\
\cline { 2 - 7 } & GL & E & PC & EC & IVE & TME \\
\hline Tratamento & 4 & $95,70^{*}$ & $43,30^{\text {ns }}$ & $192,70^{*}$ & $1,61^{* *}$ & $0,07^{\text {ns }}$ \\
Bloco & 3 & $24,20^{\text {ns }}$ & $33,80^{\text {ns }}$ & $91,93^{\text {ns }}$ & $0,59^{*}$ & $0,18^{\text {ns }}$ \\
Resíduo & 12 & 27,70 & 16,63 & 27,1 & 0,16 & 0,14 \\
\hline Média & & 44 & 30 & 50 & 3,83 & 6,85 \\
\hline CV $(\%)$ & & 11,99 & 13,46 & 10,39 & 10,55 & 5,49 \\
\hline
\end{tabular}

Tabela 2. Teor de água, emergência, emergência de plântulas em campo e índice de velocidade de emergência de sementes de amendoim tratadas com cobalto e molibdênio.

\begin{tabular}{|c|c|c|c|c|}
\hline Tratamentos & $\begin{array}{c}\text { Teor de água } \\
(\%)\end{array}$ & Emergência & EC & $\begin{array}{c}\text { Índice de velocidade de } \\
\text { emergência }\end{array}$ \\
\hline Testemunha & 6,5 & $48 \mathrm{ab}$ & $59 \mathrm{a}$ & $4,6914 \mathrm{a}$ \\
\hline Água & 7,3 & $38 \mathrm{~b}$ & $53 \mathrm{ab}$ & $3,9674 \mathrm{ab}$ \\
\hline $1,0 \mathrm{~mL}$ & 7,2 & $49 \mathrm{a}$ & $45 \mathrm{~b}$ & $3,5240 \mathrm{~b}$ \\
\hline $1,5 \mathrm{~mL}$ & 7,3 & $45 \mathrm{ab}$ & $53 \mathrm{ab}$ & $4,0173 \mathrm{ab}$ \\
\hline $2,0 \mathrm{~mL}$ & 7,1 & $41 \mathrm{ab}$ & $42 \mathrm{~b}$ & $2,9777 \mathrm{~b}$ \\
\hline
\end{tabular}

Médias seguidas de mesma letra minúscula na coluna não diferem entre si a $5 \%$ de probabilidade pelo teste de Tukey.

Observou-se que os teores de água foram próximos entre si, 6,5 e 7,1\% (Tabela 2). A proximidade destes valores é importante para que o teste de emergência e os testes de vigor não fossem afetados pelos níveis de hidratação (BRASIL, 2009; STEINER et al., 2011; MELO et al., 2016).

As variáveis porcentagem de primeira contagem e tempo médio de emergência não foram influenciadas pelos tratamentos utilizados, apresentando médias de $30 \%$ e 7 dias, respectivamente (Tabela 1). As sementes tratadas com Co e Mo não diferiram estatisticamente da testemunha em relação a emergência (Tabela 2).

Este resultado mostra que os micronutrientes até a dosagem testada não afetam a qualidade fisiológica das sementes de amendoim, mas poderão ter efeitos satisfatórios no crescimento e desenvolvimento das plantas, como observado por COSTA et al. (2013) e MELO et al. (2015) que verificaram ganhos na produção com aplicação de Co e Mo via semente.

Em relação aos testes de vigor caracterizados pela emergência de plântulas em campo e índice de velocidade de emergência, os resultados foram similares, pois foi possível observar que a 
16 e 17 de agosto de 2018, centro de convenções da FCAV/UNESP - Câmpus de Jaboticabal, SP

testemunha não diferiu das sementes tratadas com 1,5 $\mathrm{ml}$ do produto. Entretanto quando tratadas com 1,0 ou $2,0 \mathrm{ml}$ foi prejudicial ao vigor da semente de amendoim, pois apresentou resultados inferiores a testemunha (Tabela 2).

$\mathrm{O}$ vigor das sementes está relacionado à capacidade da mesma de formar plântulas normais mesmo em condições adversas de campo (CARVALHO; NAKAGAWA, 2012). Neste contexto podemos observar que as doses de Co e Mo não contribuíram para o desenvolvimento inicial das plântulas em campo, possivelmente pela baixa absorção de nutrientes durantes as fases iniciais de crescimento, uma vez que as plântulas utilizam as reservas dos cotilédones como fonte de energia para seu crescimento (SORIANO et al., 2013).

\section{CONCLUSÃO}

A aplicação de cobalto e molibdênio via semente não interfere na emergência de sementes de amendoim.

Para o vigor, o tratamento das sementes com cobalto e molibdênio prejudica a porcentagem e velocidade de emergência, não sendo recomendado no estabelecimento da cultura.

\section{REFERÊNCIAS BIBLIOGRÁFICAS}

BRASIL. Ministério da Agricultura, Pecuária e Abastecimento. Regras para Análise de Sementes. Secretaria de Defesa Agropecuária. Brasília: MAPA/ACS, 2009. 395 p.

CARVALHO, N. M.; NAKAGAWA, J. Sementes: ciência, tecnologia e produção. 5.ed. Jaboticabal: Funep, 2012, 590p.

CONAB. Companhia Nacional de Abastecimento. Acompanhamento de safra brasileira: grãos. Brasília, 2018. Disponível em: https://www.conab.gov.br/info-agro/safras/graos/boletim-da-safra-degraos. Acesso em: 13 de maio de 2018.

COSTA, D. S.; VIANA, J. S.; MELO, L. D. F. DE A.; MORAES, G. S. DE; CORDEIRO JÚNIOR, J. F., MARCOS, H. S. B.; FIGUEREDO, H. A. Produtividade de amendoim influenciado pela aplicação de nutrientes e fitoestimulante. XIII Jornada de Ensino, Pesquisa e Extensão, UFRPE, Recife-PB, Anais XIII JEPEX, (CD-Rom), 2013.

DOMINATO, J. Dissertação (mestrado em agronomia-Produção Vegetal) Calcário e gesso na semeadura do amendoim combinados com adubação boratada foliar. Presidente Prudente: Universidade do Oeste Paulista, 32p. 2010.

LABOURIAU, L. G.; VALADARES, M. E. B. On the germination of seeds Calotropis procera (Ait.) Ait.f. Anais da Academia Brasileira de Ciências, v. 48, n. 2, p. 263-284, 1976.

MAGUIRE, J. D. Speed of germination-aid in selection and evaluation for seedlings emergence and vigor. Crop Science, v. 2, n. 1, p. 176-177, 1962. 
MELO, L. D. F. A.; GONÇALVES, E. P. RALPH, L. N.; VIANA, J. S.; SILVA, S. C. A. Physiological and Physical Quality of Seeds from Peanut Seeds and Plants under the Influence of Fertilizer and Biostimulant. American Journal of Plant Sciences, v. 6, n.2, p. 1594-1606, 2015.

MELO, L. F.; MARTINS, C. C.; DA SILVA, G. Z.; BONETI, J. E. B.; VIEIRA, R. D. Beneficiamento na qualidade física e fisiológica de sementes de capim-mombaça. Revista Ciência Agronômica, v.47, n.4, p. 667-674, 2016.

SORIANO, D.; HUANTE, P.; BUEN, A. G.; OROZCO-SEGOVIA, A. Seed reserve translocation and early seedling growth of eight tree species in a tropical deciduous forest in Mexico. Plant ecology, v. 214, n.11, p. 1361-1375, 2013.

STEINER, F.; OLIVEIRA, S. S. C. D.; MARTINS, C. C.; CRUZ, S. J. S. Comparação entre métodos para a avaliação do vigor de lotes de sementes de triticale. Ciência Rural, v.41, n.2, p.200-204, 2011.

VIEIRA, C. Adubação mineral e calagem. In: VIEIRA, C.; PAULA, JR, T. J.; BORÉM, A. (Ed.).

Feijão: aspectos gerais e cultura no Estado de Minas. Viçosa: UFV, 1998. p. 123-152. 